\title{
FASTRAC NOZZLE DESIGN, PERFORMANCE AND DEVELOPMENT
}

\author{
Warren Peters, Pat Rogers. Tim Lawrence. Darrell Davis, Mark Dagositino. Andy Brown \\ NASA Marshall Space Flight Center \\ Huntsville. Alabama 35812
}

\begin{abstract}
With the goal of lowering the cost of payload to orbit. NASA/MSFC (Marshall Space Flight Center) researched ways to decrease the complexity and cost of an engine system and its components for a small two-stage booster vehicle. The composite nozzle for this Fastrac Engine was designed. built and tested by MSFC with fabrication support and engineering from Thiokol-SEHO (Science and Engineering Huntsville Operation). The Fastrac nozzle uses materials, fabrication processes and design features that are inexpensive. simple and easily manufactured. As the low cost nozzle (and injector) design matured through the subscale tests and into full scale hot fire testing. X-34 chose the Fastrac engine for the propulsion plant for the X-34. Modifications were made to nozzle design in order to meet the new flight requirements. The nozzle design has evolved through subscale testing and manufacturing demonstrations to full CFD, thermal, thermomechanical and dynamic analysis and the required component and engine system tests to validate the design. The Fastrac nozzle is now in final development hot fire testing and has successfully accumulated 66 hot fire tests and 1804 seconds on 18 different norzles.
\end{abstract}

\section{INTRODUCTION}

The goal of this paper is to describe the purpose. design, performance, and the process that led us to the final flight nozzle design.

Our component has a one-piece liner and a one-piece bonded structural sfll that is continuous from the supersonic chamber, through the throat to the supersonic exit. For expediency, we will refer to this entire structure as the "nozzle" rather than the "chamber/nozzle".

The Fastrac Nozzle is the structural backbone of the Fastrac Engine, which operates at the following conditions.

PC

Propellants

Overall (Total) MR

Wall Film Cooling

Ignition

Thrust

Area Ratio (Flight)
$633 \mathrm{psi}$

2.34 (includes film cooling)

$10 \%$ of total fuel flow

Hypergolic, through wall

$60,000 \mathrm{lbs}$

$30: 1$
LOX/RP-1

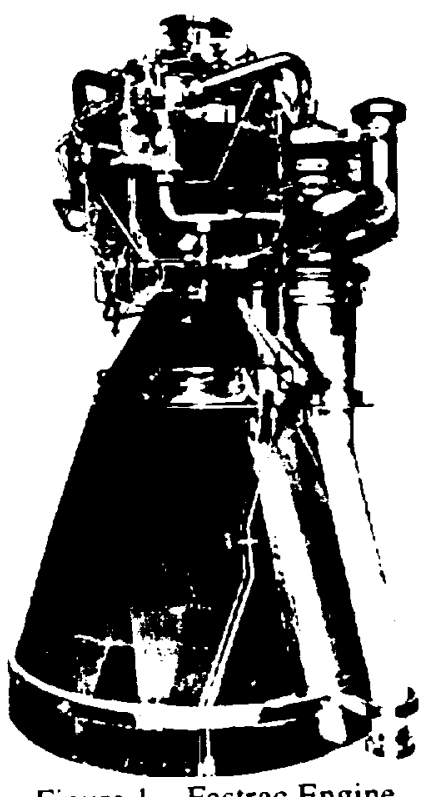

Figure I - Fastrac Engine

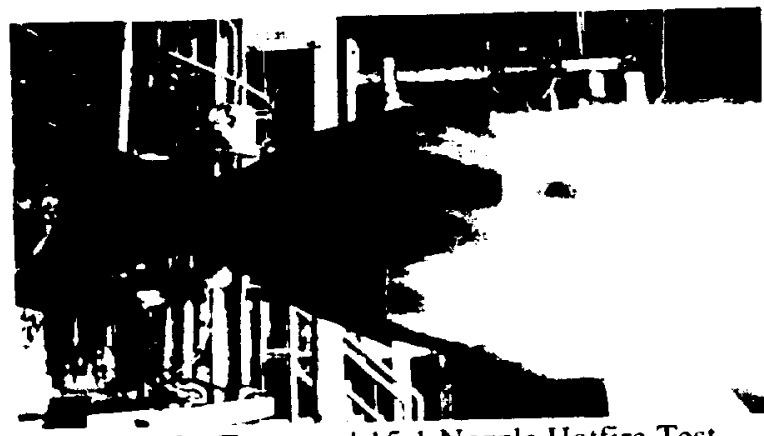

Figure 2 - Truncaled 15:1 Nozzle Hotfire Test

Copyright $(1) 2000$ by the American Institute of Aeronautics and Astronautics. Inc. No copyright is asserted in the Linited States under Title 17, U.S. Code. The L'.S. Government has a royalty-free license to exercise all rights under the copyright claimed herein for Governmental Purposes. All other rights are reserved by the copyright owner. 


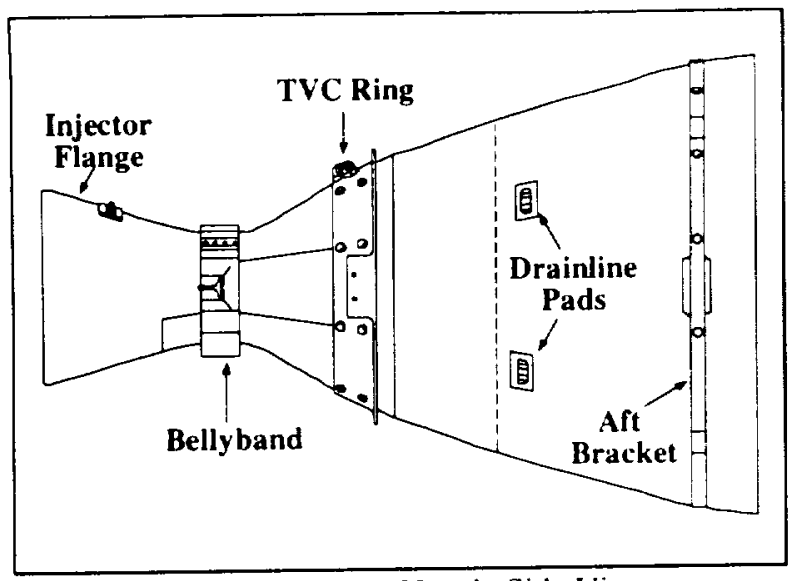

Figure 3 - Fastrac Nozzle Side View

\section{DESIGN}

The Fastrac Nozzle is a one-piece, composite, ablative thrust chamber. The liner is a tape-wrapped ablative that is encased in a filament-wound structural overwrap. with no mechanical joints in the composite. Interface hardware is fabricated out of 304 stainless steel and bonded to the composite, with mechanical locks in high temperature and stress locations.

\section{A. Geometry}

The throat diameter is 8.25 inches and has an area ratio of approximately 30:1. The subsonic chamber contour is optimized for the use of fuel film cooling on the wall. the supersonic nozzle contour is optimized for an altitude start. The throat geometry is designed to reduce the performance impact of throat erosion. In order to prevent over expansion of the exhaust gas, and the associated side loads, the nozzle is sometimes truncated to an area ratio of $15: 1$.

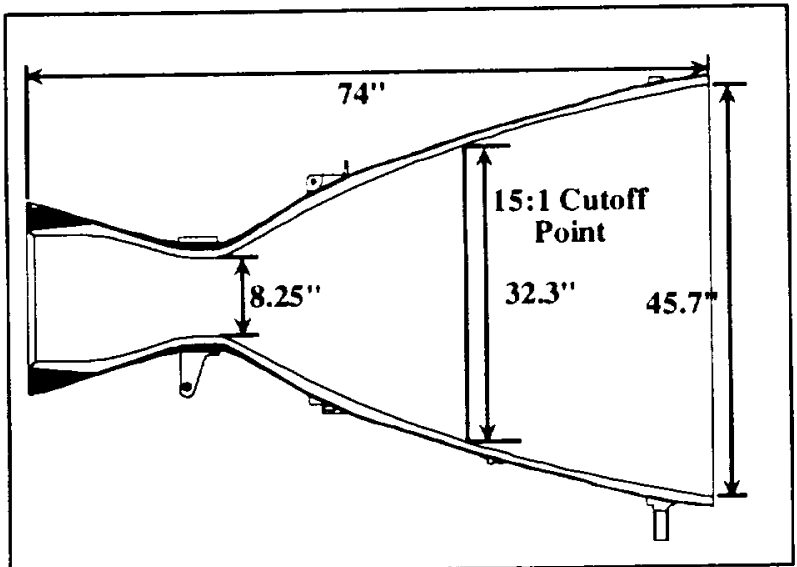

Figure 5 - Fastrac Nozzle Dimensions

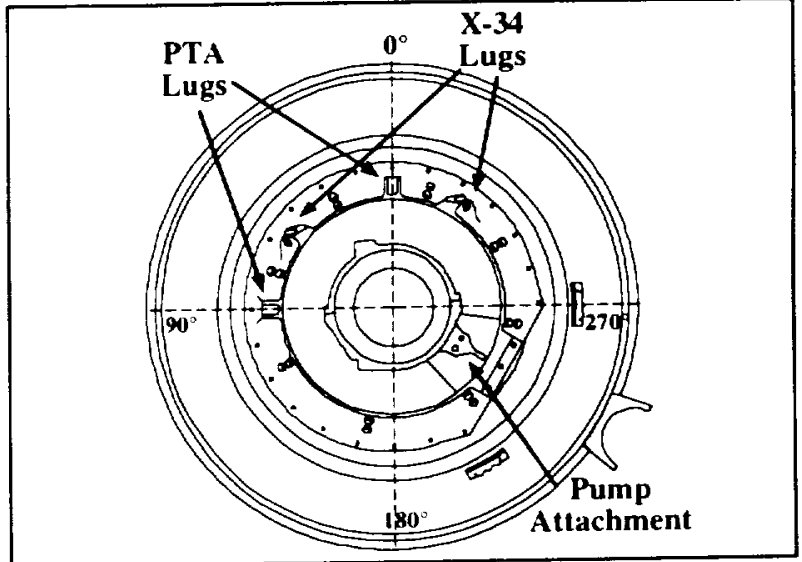

Figure 4 - Fastrac Nozzle Top View

\section{B. Materials and Fabrication}

The ablative liner is tape-wrapped using Silica Phenolic tape and then cured on the tape-wrap mandrel. After external machining of the liner, the injector attachment flange is bonded to the exterior of the liner. Carbon Epoxy overwrap is then filament wound around the entire structure and cured. The overwrap tooling is cut off and the nozzle is machined to the correct length. The 304L Stainless brackets and external attach points are bonded to the nozzle outer surface with paste adhesive. Sheet Cork TPS (Thermal Protection System) is applied to the outer surface aft of the TVC bracket for flight configuration.

All of the nozzles are fabricated and assembled at NASA/MSFC by Thiokol-SEHO and ASRI.

\section{Brackets}

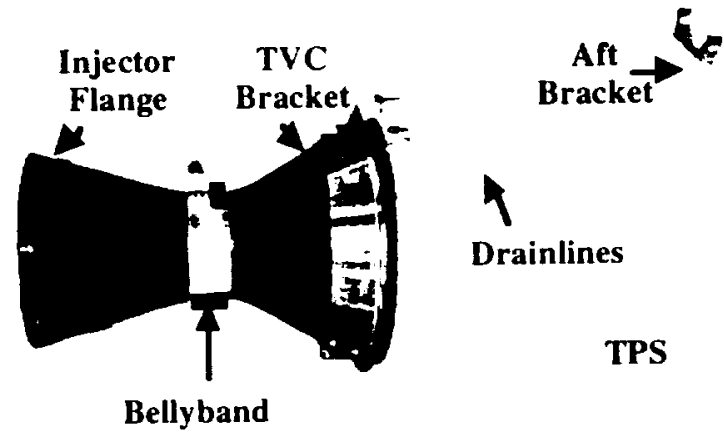

Figure 6 - Fastrac Bracket Locations

Injector Flange - has threaded bolt holes in the top, and provides a metal joint to mate to the injector. Chamber Pressure, seal pressure and ignitor ports are drilled through the nozzle near the injector. The metal in the flange is threaded for good seating of the instrumentation. 
Bellyband - is a multipurpose 2-half bracket that is bonded to the nozzle and bolted together at the throat location. It provides the lower attachment for the Turbopump, stringer bracket attach points and handling points.

TVC Bracket - contains 2 sets of TVC (Thrust Vector Control) lugs, the heat shield attachment flange. drainline passages and the GG (Gas Generator) Exhaust Duct attachment. This bracket is bonded to the nozzle $\mathrm{OD}$, and also pinned in place with $304 \mathrm{~L}$ stainless bolts to provide extra strength in this highly loaded joint.

Alt Bracket - provides the lower altach point for the GG Exhaust Duct, but also has drainline attach points. This bonded bracket is also pinned because of the high temperature that the bond joint will see on re-entry.

A liew molded polymer brackets are bonded to the nozzle to provide intermediate attachment of the drainlines and stringer brackets.

\section{PERFORMANCE}

\section{A. Hotfire Testing}

The table below represents the hot fire testing of the Fastrac Nozzle. This table includes only testing on the $60,000 \mathrm{lb}$. thrust hardware, and does not include the subscale testing that led to the $60 \mathrm{~K}$ design.

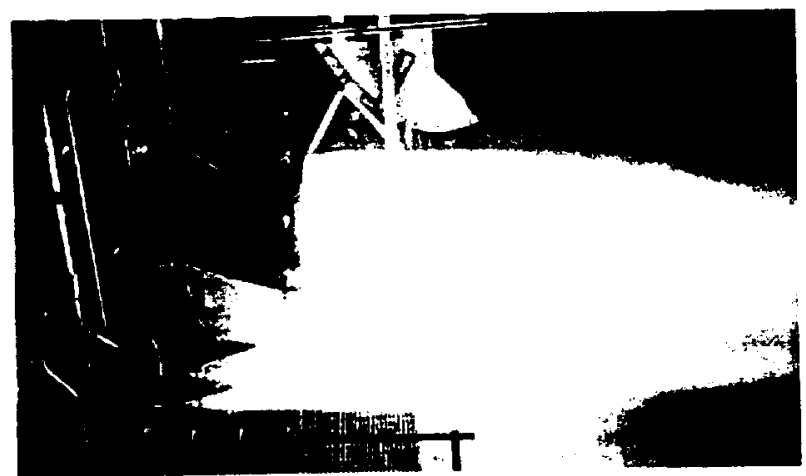

Figure 7 - Overexpanded 30:1 Nozzle Test

\begin{tabular}{|c|c|c|c|}
\hline & $\begin{array}{c}\text { Component } \\
\text { Test }\end{array}$ & $\begin{array}{c}\text { Engine } \\
\text { Test }\end{array}$ & Total \\
\hline $\begin{array}{c}\text { Hot Fire } \\
\text { Tests }\end{array}$ & 36 & 30 & 66 \\
\hline $\begin{array}{l}\text { Hotfire } \\
\text { Seconds }\end{array}$ & 1246 & 557 & 1803 \\
\hline $\begin{array}{c}\text { Nozzles } \\
\text { Used }\end{array}$ & 12 & 6 & 18 \\
\hline
\end{tabular}

Figure 8-Nozzle Test Summary
We have performed 6 full duration tests plus two tests that were cut just before planned duration (facility related). The Fastrac nozzle is not designed for multiple use. but we have carefully inspected the nozzles and reused them to reduce the cost of the engine development testing. One 15:1 nozzle has been tested for: $150 \mathrm{sec}, 12 \mathrm{sec}, 30 \mathrm{sec}$ and $150 \mathrm{sec}$ for a total of 342 seconds and 4 starts. One 30:1 nozzle has been tested for: $12 \mathrm{sec}, 24 \mathrm{sec}, 24 \mathrm{sec}, 24 \mathrm{sec}, 24 \mathrm{sec}, 24 \mathrm{sec}$ and $150 \mathrm{sec}$ for a total of 282 seconds and 7 starts.

\section{B. Erosion Rate}

A typical operating condition of an ablative material is that the material that is charred during the pyrolization process, and this weak insulating material is removed by the hot gas. This removal of material is termed recession or erosion. When the material at the throat erodes, the throat diameter increases, which decreases the area ratio and significantly reduces Isp. After 66 hotfire tests and 1803 seconds, every nozzle throat diameter has measured the same diameter or smaller after a hot fire test. Solid carbon is deposited, by the combustion products, on the nozzle throat surface during firing and during shutdown, but this material is removed for the diameter measurements. We have found no erosion of the silica material.

\section{Iniector/Wall Compatibility}

The interaction between the chamber wall and the injector flow has a direct effect on the life and performance of the nozzle wall. Any mal-distribution of the hot gas flow from the injector can cause local hot spots on the chamber wall. Because the liner material is an excellent insulator, any localized heating on the wall is not conducted quickly to surrounding material. and the possibility of a deep removal of the ablative material is possible. We define this removal of material as a "streak".

The Fastrac nozzle has shown excellent compatibility based on our extensive hot fire data base. Our testing has revealed that if a fuel film cooling ( $f(f)$ ) hole is blocked, it will not result in a streak. One nozzle did receive a shallow streak during a full duration hot fire test due to facility contamination blocking an injector fuel element. After the contamination was removed, an additional 3 tests and 192 seconds were put on that nozzle with no subsequent damage to the nozzle wall. Streaks caused by hot gas flow mal-distributions were eliminated in the subscale testing by varying injector element geometry.

\section{Thermal Analysis and Test}

Thermal predictions for the nozzle are generated from a thermal math model using a finite difference analysis software (SINDA) and custom Fortran codes. The model accounts for the kinetic decomposition of the 
silica phenolic liner material and can predict char and heat affected depths. The model was calibrated with thermal analog tests performed at Southern Research. Inc., and verified by matching the response of thermocouples imbedded in the liner of two $60 \mathrm{~K}$ Fastrac nozzles. The model can predict temperature gradients at any axial location and is especially useful for predicting temperatures of the bondline between the silica phenolic liner and graphite epoxy overwrap. Due to the low thermal conductivity of the liner, the peak bondline temperatures occur several hundred seconds after the shutdown of the engine. The liner thickness was sized to keep all of the liner-to-overwrap bondline below $200^{\circ} \mathrm{F}$ during operation, and below $300^{\circ} \mathrm{F}$ at the critical external attachment regions during the heat soak back after engine shutdown.

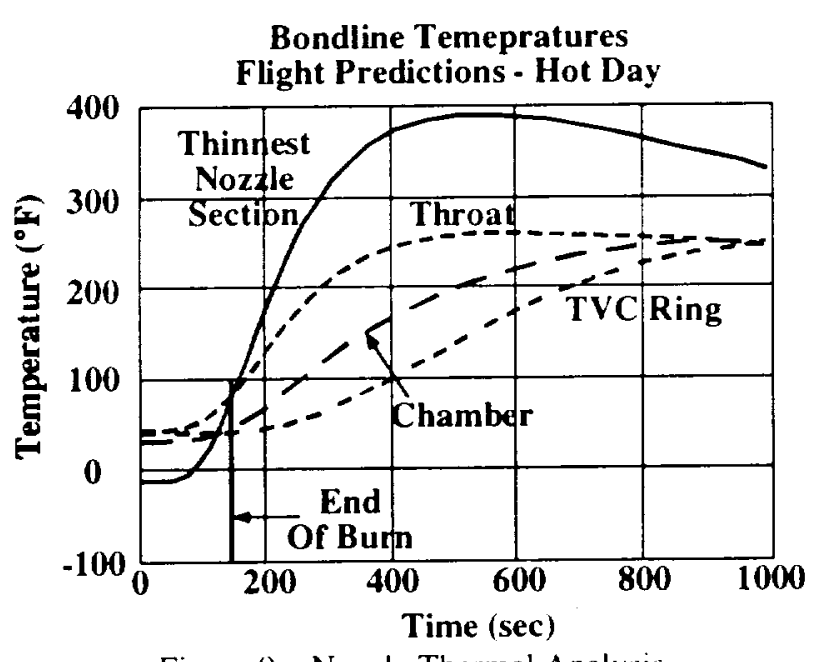

Figure 9 - Nozzle Thermal Analysis

\section{E. Sideloads Analysis and Test}

The Fastrac nozzle was designed to be launched at an altitude of $30,000 \mathrm{ft}$. and was optimized for the ambient pressure at that altitude. In order to prevent nozzle separation and the resulting unsteady side loads on a ground test, the rule of thumb is that the (nozzle exit pressure) / (ambient pressure) should be $>0.3$. Diffusers are usually required for testing overexpanded nozzles, but a diffuser is expensive and time consuming to build. We decided to determine the limits of testing a 30:1 nozzle at sea level with no diffuser present. The nozzle was tested in the component stand (TS116) at $\mathrm{MSFC}$ in order to minimize risk to the engine.

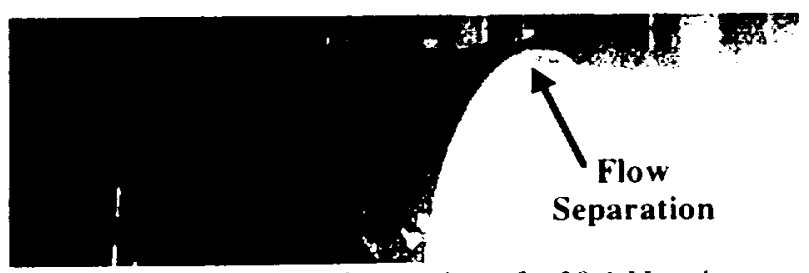

Figure 10-Flow Separation of a 30:1 Nozzle
On each hot fire test of a $30: 1$ nozzle the flow has separated approximately 12 inches from the exit plane. The exit pressure of the exhaust is equal to $1 / 3$ of the ambient pressure at this location, just as the rule of thumb predicts.

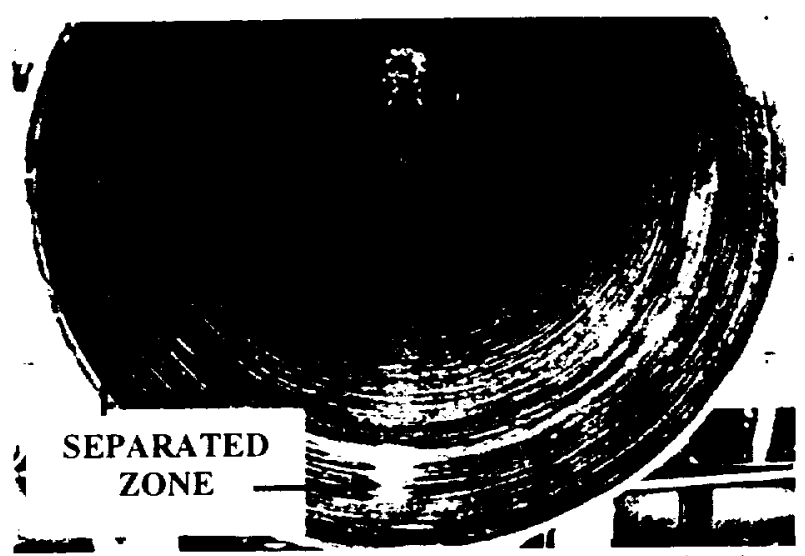

Figure 11. Flow Separation Line of A Fired Nozzle

The sideloads measured during 30:1 HTF engine tests ware 2000 lbs. maximum (translated to nozzle lip) at approximately $15 \mathrm{HZ}$. The peak sideloads occur during startup and shutdown. but do not induce any damage to the nozzle due to the high nozzle stiffness. The location of the separation is easily seen in the photograph above. The change in color is due to the aspiration of air into the aft 12 inches of the nozzle affecting the deposition of carbon to the nozzle wall.

The Fastrac engine transient startup and shutdown side loads were calculated using a two dimensional nowficld program and an empirically based sideload prediction program. The JANNAF standard TwoDimensional Kinetics Program (TDK97) was used to predict nozzle inside wall pressures. It is a method of characteristics based supersonic flowfield prediction program. The MABL boundary layer module was used for the Fastrac case. Once full and reduced power level wall pressures were known, the Rocketdyne developed Sideload program was used to predict maximum possible sideload magnitudes during engine startup and shutdown. The Sideload program determines the side force resulting from a separated nozzle flowfield canted at an angle. The program assumes that the separation plane begins and ends at two user defined pressure ratios of Pwall / Pambient. The pressure ratios used for Fastrac were 0.3 and 0.25 . These ratios were selected based on data from Space Shuttle Main Engine tests. Resulting sea level side load maximum magnitudes were 800 pounds for the $15: 1$ area ratio nozzle and 2100 pounds for the $30: 1$ area ratio nozzle.

4

American Institute of Aeronautics and Astronautics 


\section{F. Thermostructural Analysis}

We use Patran to pre-process (huild) and, to some extent. post-process (interpret results from) our models. We use the ABAQUS finite element code to run the models. We also make extensive use of internally developed FORTRAN codes and Excel spreadsheets to process composite material properties for input and to post-process the output analysis results. In order to approximate the continuous variance in overwrap material properties along it's length. there are over 40 different overwrap material property definitions for a 30:1 nozzle. and each set has to be pre- and postprocessed individually. Liner material properties vary over temperatures from -50 to over 2500 degrees F.

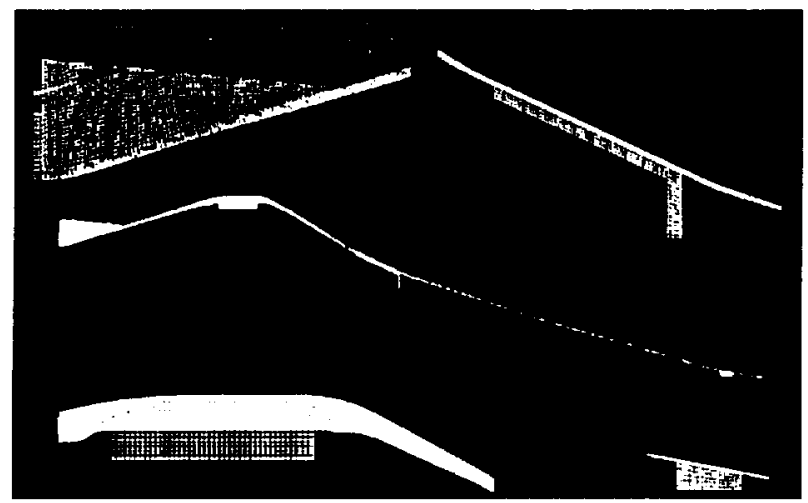

Figure 12 - Thermomechanical Model Grid

\section{G. Dynamic Analysis and Test}

Because the nozzle is the structural backbone of the FASTRAC engine. its structural dynamic characteristics will have a large influence on induced engine loads. To facilitate the dynamic analysis, in which numerous load cycles requiring computationally intensive modal analyses are performed, a $360^{\circ}$ MSC/NASTRAN plate element model was created. These plate elements incorporate the properties of each layer in the composite layup, but several material coordinate transformations are required initially to obtain properties that can be input into NASTRAN. These transformations take the measured warp and fill anisotropic properties of the silica phenolic liner and incorporate the changing wrap angle to yicld tangential and longitudinal Young's Moduli. Shear Moduli, and Poisson's ratios. All of these values change continuously along the axial length of the nozzle; this is represented by a using different set of properties for each axial row (72 total rows) of plate elements.

A series of frec-frec modal tests of varying conligurations of the nozele was pertormed. along with a "hot" modal test. on which acelerometers were active during a full duration hotfire. Theses were used (1) correlate the dynamic models. The method used for correlation was to scale each of the independent material properties in the model until an acceptable value of natural frequency was obtained and an acceptable Modal Assurance Criteria (MAC) obtained for the modes. The final results were very good, with the correlated model for the $30: 1$ nozzle having frequencies within $10 \%$ of the measured frequencies and $\mathrm{MAC}$ values greater than 0.9

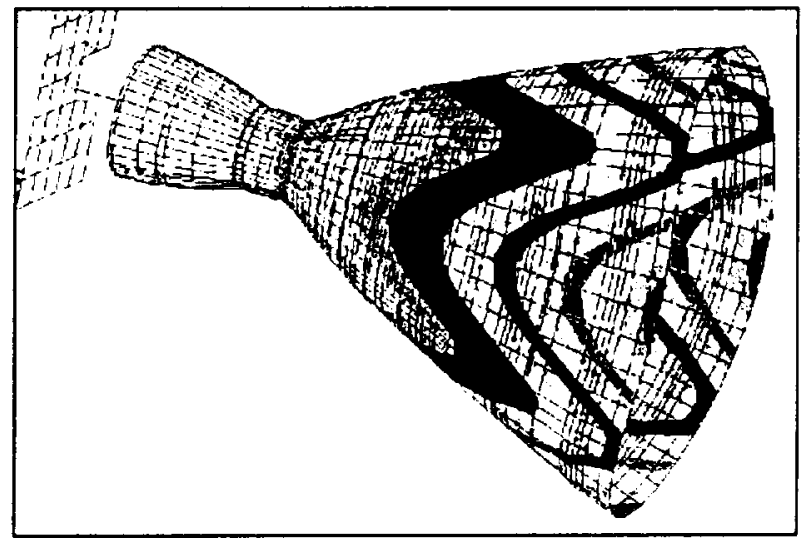

Figure 13 - Calibrated Dynamic Model

\section{PHILOSOPHY}

In order to meet the general design requirements of a low cost engine system, we chose an ablative liner with a filament wound structural overwrap for the nozzle. An ablative system has three significant advantages for a booster application. The first advantage is that no regenerative cooling is required for the nozzle, which significantly reduces the complexity of the engine system and nozzle. The second advantage is that the fabrication time of our nozzle is only 4 to 6 weeks (assuming brackets and material are in hand). The third advantage is that our composite nozzle is very low cost compared to regen nozzles (our current cost is approximately $\$ 150 \mathrm{~K}$ for a $30: 1$ nozzle with Thermal Protective System)

\section{A. Materials Selection - Liner}

We anticipated using film coolant to reduce the wall temperature. Using film cooling to cool the wall down to a temperature that was acceptable for a standard metal would have produced a significant performance drop. High temperature materials such as ablatives, ceramic composites or refractory metals would still be needed. In the attempt to balance the performance with cost, we eliminated materials such as the refractory metals and ceramic composites. Although ceramic composites and relractory inetals have excellent performance characteristics in both weight and temperature capability, their high cost was prohibitive for our low cost, quick manufacturing requirements. 
Our Choices were now limited to ablative materials. We consulted existing databases for different ablative materials that included cost, density, and erosion performance. There were lower cost materials. such as DC 93-104, that were less expensive to manufacture. but had high erosion rates that would significantly reduce performance. There were materials with a promise of better performance, such as quartz phenolic, but the extra cost did not look worth the slight increase in temperature capability.

We felt that Silica Phenolic and Carbon Phenolic were the two best choices for the liner of our nozzle. Extensive material databases. analytical modeling and manufacturing capabilities are available because of their use on the Solid Rocket Boosters (SRBs). There was no data available to compare the performance of silica phenolic and carbon phenolic in our hot gas environments using LOX/RP-1. Carbon phenolic has a higher temperature capability than silica phenolic. but is much more sensitive to the oxidizing environment that is produced by LOX/RP-I propellants. Based on this, we decided to baseline silica phenolic in our Fastrac 1 Liner Material Demonstration. Carbon phenolic was to be the backup material if the silica performance was not acceptable. Evidence of throat erosion has not been found after our extensive hotfire testing. The throat has measured the same before and after every hotfire test. within a measurement tolerance of 0.01 inches.

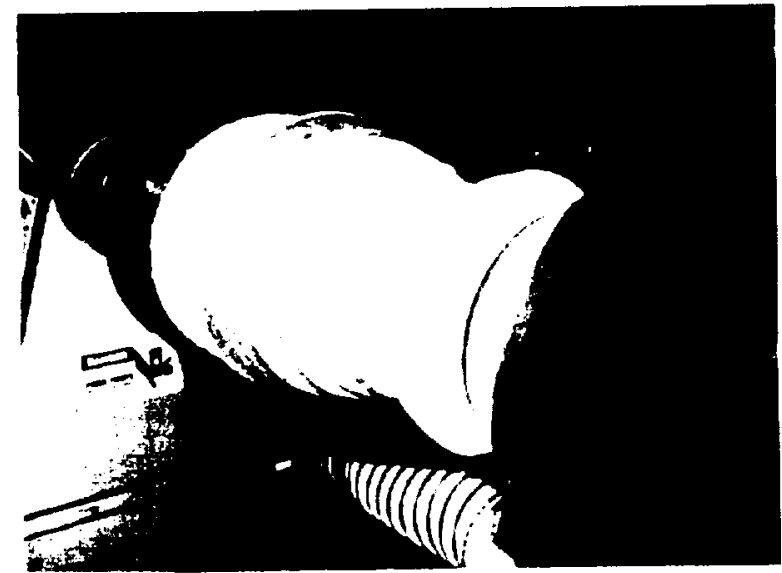

Figure 14 - Tape Wrapping of Silica liner (40K)

Our largest deficiency was in the material database for the silica phenolic. Extensive properties needed for thermal and thermostructural analysis existed for temperatures up to $300^{\circ} \mathrm{F}$. However, properties were not available for higher temperatures because the database was developed for the SRB. which only used the silica phenolic as a hackside insulator. Silica phenolic specimens were made at MSFC and sent to Southern Research for the generation of high temperature properties

\section{B. Materials Selection - Overwrap}

A structural jacket is needed to encase the ablative liner material. Many applications use a steel structure to house an ablative liner. This metal structural approach tends to be simple and heavy, or relatively lightweight and difficult to manufacture. Our search targeted lightweight composite materials that were easily manufactured.

The two methods of overwrap that were considered were filament winding and tape wrapping. One method of applying overwrap is to wrap over the liner with tape in the same manner you would wrap a baseball bat handle with grip tape. We were told that our tapewrapping machine was not capable of providing this geometry because it could not follow the complex outer surface of the nozzle. so this option was dropped. The option we chose was filament winding. We have the ability to make large filament would items at MSFC.

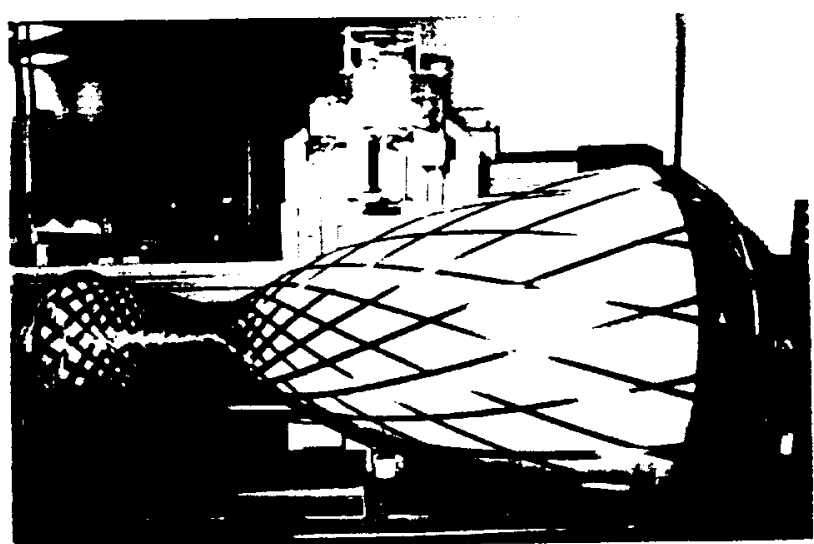

Figure 15 - Filament Winding The Overwrap (40K)

The two most common overwrap systems for this type of application are glass-epoxy and carbon-epoxy. We chose to use the carbon-epoxy because the higher stiffness and lower weight would provide a stiffer, lighter weight nozzle than the glass-epoxy. Glassepoxy is still a strong choice because it more closely matches the thermal coefficient of expansion (CTE) of the silica liner. Using glass epoxy overwrap should reduce the residual stress created during the final cure of the nozzle, but the nozzle would also be expected to be less stiff due to the lower stiffness of the glass fiber. The winding pattern over this hourglass shape proved to be quite a challenge. but the pattern finalized so that the fibers do not bridge (leave a gap) along the nozzle.

\section{DESIGN PROCESS}

\section{A. Liner Material Demonstration (15K)}

We chose silica phenolic as the liner material, but we did not have access to any hot fire data using LOX/RP- 
I propellants. We needed to quickly and efficiently hotfire the silica phenolic liner using the correct conditions and injector to develop data for injector/chamber compatibility, throat erosion and how the wall fuel film cooling would affect the TCA performance.

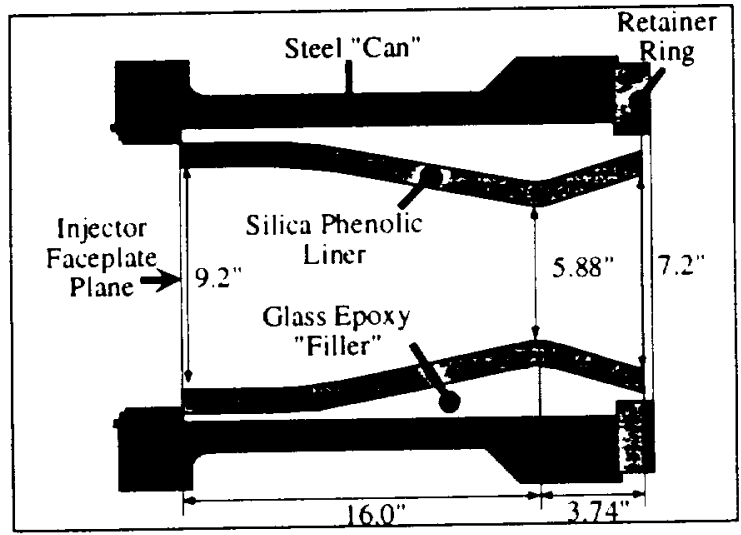

Figure 16-15K "Fastrac-1" Chamber

\section{1. $15 \mathrm{~K}$ Design}

We built a subscale materials tester that was modified from existing hardware left over from the STME program. This chamber/nozzle configuration was considered a liner materials test because the liner was captured in a metal jacket that was never intended to be a flight design. We could make these liners quickly and inexpensively and slide them into the metal "can" for fast turn-around on the test stand. The injector had a flight like faceplate design to properly evaluate TCA performance along with the correct heating to the chamber wall.

\section{Operating conditions}

Propellants

LOX/RP-1

Mixture Ratio 2.34 (Includes fuel film cooling)

PC 350 - 500 psia

Wall Cooling $10 \%$ of fuel flow on walls

\section{Eabrication Process}

The ablative liner of the Fastrac-1 ( $15 \mathrm{~K}$ ) configuration was made using the processing methods that we intended to use for "flight-like" situations. This liner. however, was overwrapped with a glass epoxy filler that was not intended for a tlight design. The glass epoxy filled in the outer area around the throat and chamber and provided a cylindrical outer shape. The outer diameter of the cylinder was then machined and bonded into the steel jacket with RTV. The last step was to bolt a steel retainer ring onto the aft end of the jacket to provide a mechanical lock for the liner.

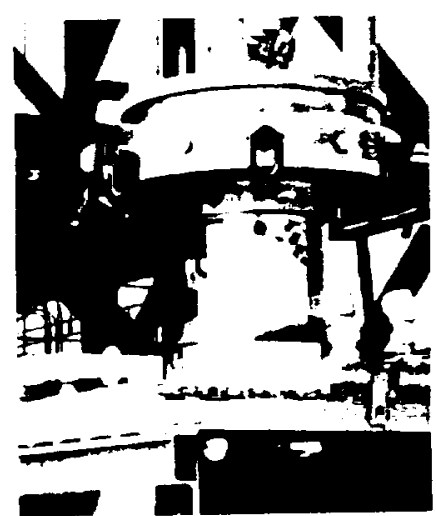

Figure $17-15 \mathrm{~K}$ TCA Mounted In Test Stand

\section{Film Coolant Study}

We knew that some wall cooling would be necessary to keep the silica phenolic liner below its melting temperature (approx. $3200^{\circ} \mathrm{F}$ ) so that the throat erosion would be held under the requirement of 2 mils per second. Below this temperature. the silica phenolic will pyrolize and form a structurally weak, but insulating char layer that is not eroded (removed) quickly. If the wall is above this temperature, the silica melts and is much more rapidly removed from the surface causing high erosion rates. A CFD trade study was conducted on the affect that different film coolant flowrates and chamber length had on throat erosion. The only erosion data that we had to base our calculations on was derived from the MI program conducted in the late 1960's (see AIAA 69-442)'. This chamber was a large LH2/LOX TCA with a silica phenolic chamber. The results of the CFD analysis using the MI erosion data showed that approximately $10 \%$ of the fucl should be used as film coolant to keep chamber walls of the $15 \mathrm{~K}$ chamber below $3200-36000^{\circ} \mathrm{F}$. The inner contour of the chamber was designed to maximize the affect of the fuel film cooling that is provided by the injector while optimizing the total efficiency of the TCA.

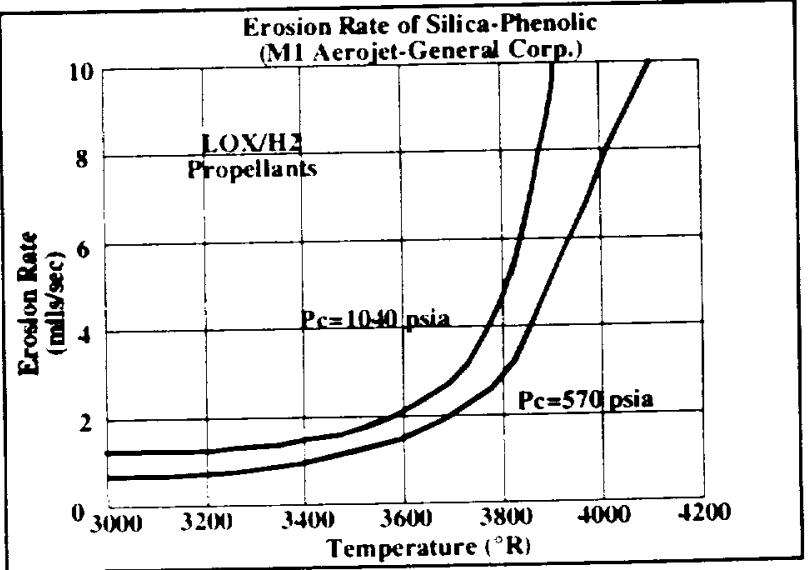

Figure 18 - M1 Erosion Rates From AIAA 69-442 


\section{Hotfire Test Results}

A test matrix of 31 hotfire tests and 778 seconds was accumulated on 7 different $15 \mathrm{~K}$ liners. No throat erosion was measured on any of the liners. The silica liner was charred but none of the charred material was removed. Chamber streaking was a consistent problem throughout the entire test program, and was solved by changing the injector element geometry to block LOX rich gas from flowing parallel to the injector face and against the wall. A combination of element placement. impingement heights and hole diameter were used to even out the injector flow distribution.

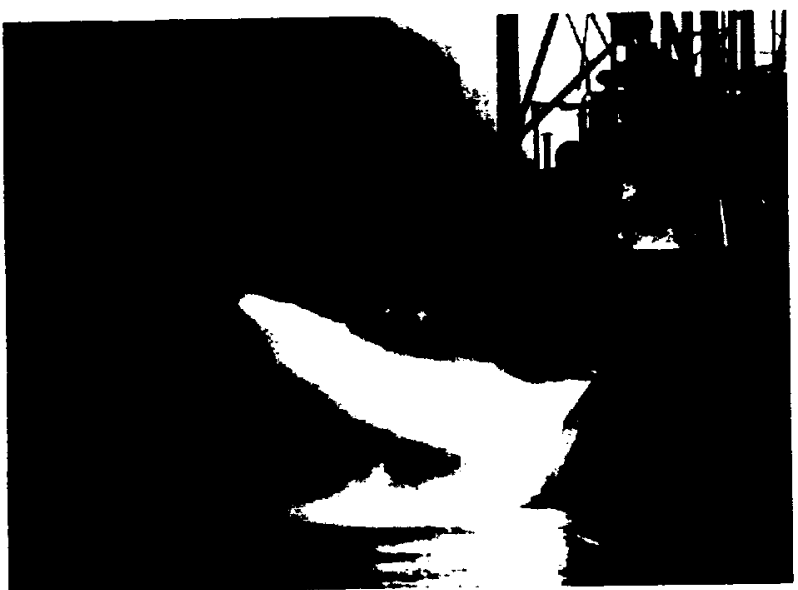

Figure 19-15K TCA Hot Fire Test at MSFC/ TS 116

\section{B. Fabrication Demonstration and Test (40K)}

\section{Fabrication and Test Goal}

As the $15 \mathrm{~K}$ hardware was showing sucecss in manutacturing and hotfire. we hegan the next development phase of the nozzle. The second portion of the program was the $40 \mathrm{~K}$ thight-like thrust chamber assembly (TCA). It was named $40 \mathrm{~K}$ because the TCA would produce approximately $40.000 \mathrm{lbs}$. of thrust at 400 psi. The goal of this portion of the development program was to demonstrate that a Hight-like nozzle could be manufactured using the materials and techniques mentioned above. Manufacturing a continuous, hourglass shaped liner is not a common manufacturing method and had to be proven. Most ablative nozeles are manufactured in segments and joined by mechanical means. which significantly increases the cost and complexity of the norzle. CFD, thermal and thermostructural analysis began hefore hot fire testing, hut the primary purpose of the $40 \mathrm{~K}$ hardware was to collect data. That data was used to huild and validate the detailed models for the $60 \mathrm{~K}$ thight design. Three of these nomples were manufactured and went on 10 successfully complete an accumulated 18 kests and 47.3 seconds of hot lite. with the longest test 150 seconds long. Injector performance. chamber/injector compatibility and throat erosion were evaluated.

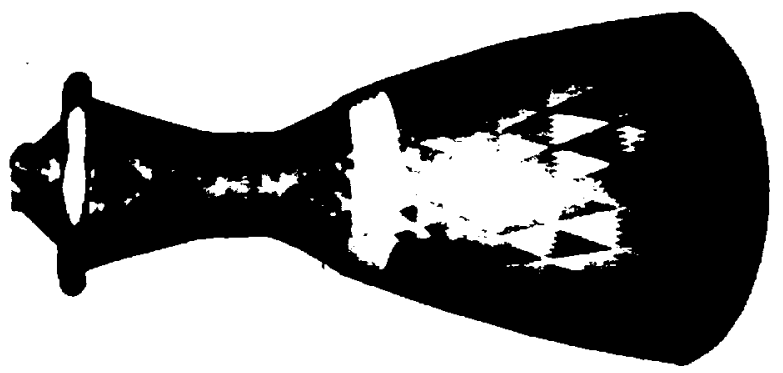

Figure $20-40 \mathrm{~K}$ TCA With Mock TVC Ring

\section{Internal Geometry}

The $40 \mathrm{~K}$ supersonic nozzle was designed for an area ratio of $30: 1$, but was truncated at an area ratio of $10: 1$ to keep from over expanding the exhaust gas. (Pexit/Pamb > 3 rule) The 400 psi chamber pressure intended for the $40 \mathrm{~K}$ nozzles limited the area ratio to $10: 1$. The shape of the internal wall of the subsonic chamber was designed using the CFD analysis and hotfire data obtained from the Fastrac-l (15K) hardware. Based on advice from highly experienced personnel from Thiokol, we also added a 1.5 inch cylinder section at the throat. The purpose of this addition was to try to reduce the effect that throat erosion would have on the performance of the TCA. (Reducing the throat diameter will decrease the area ratio and drop the Isp of the nozzle) The maximum heat transfer location is just upstream of the throat, and that is where you would expect to get the most erosion. By adding more material (length) to this area you would diminish the chance of eroding the entire throat, and preserve or delay the affect on the Isp. In hindsight, this may not be necessary since there is not erosion in the throat.

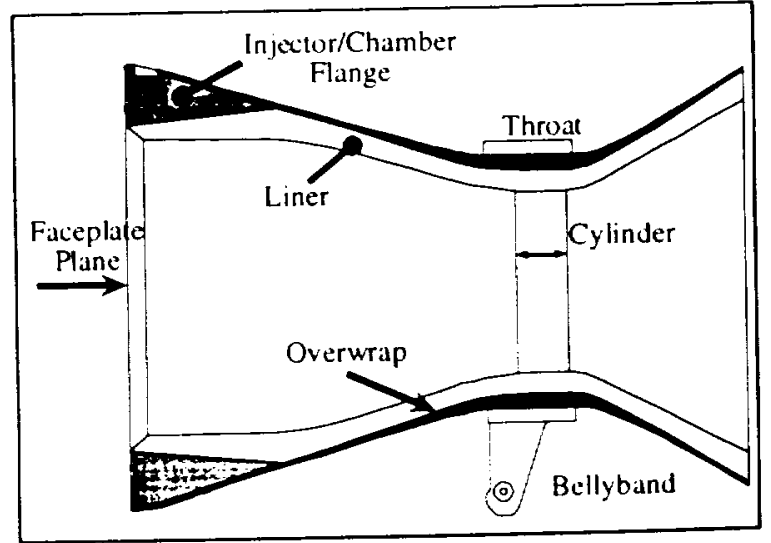

Figure 21 - Fastrac Chamber Design 


\section{Initial Thickness of Materials}

The thickness of the liner is not arbitrary, but is constrained by manufacturing limitations. The initial liner thickness of the chamber and nozzle was driven by manufacturing guidelines, the geometry of the chamber/injector flange and the amount of char we saw in the $15 \mathrm{~K}$ test series.

The thickness of the overwrap is also governed by the filament winding process. When you use a filament winding process you cannot independently change the thickness of the overwrap along the length of the nozzle. You choose the thickness at the largest diameter, and that drives the thickness at all other locations. The thickness relationship is roughly (not exactly) equivalent to the following. Assume an overwrap thickness at the largest diameter and calculate the cross sectional area of the overwrap at that plane. The overwrap cross sectional area is constant for the entire nozzle. The same amount of material will be placed at the throat as there is at the exit. Since the throat is much smaller in diameter, the overwrap will be much thicker at that location.

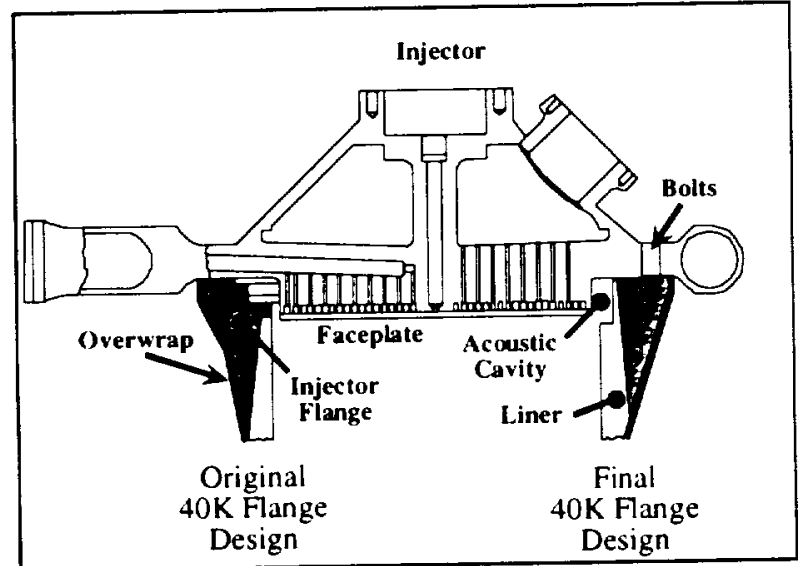

Figure 22 - Injector Altachment Design

\section{Injector Attachment Design}

The chamber is attached to the injector by a metal flange that is bonded into the composite. A taper is machined into the OD of the chamber, and the flange is bonded onto the liner. Adhesive is then applied to the entire surface of the nozzle (including the flange) and the nozzle is overwrapped. This joint is bonded on both sides of the steel flange. The outer surface of the flange was originally designed with a concave surface so that we could reduce the weight of this large piece of steel. We were unable to keep the overwrap fibers from bridging the concave surface, so the OD of the flange was changed to the current design.

\section{Tooling}

The design and fabrication of the tapewrap mandrel should not be underestimated. The mandrel is large and requires high tolerances, which makes the fabrication non-trivial. Although we put significant effort into the tooling, it can be reused for the life of the program. We are currently using the original tape-wrap mandrel for our $56^{\text {th }}$ nozzle.

\section{Hotfire Test Results}

A test matrix of 18 hotfire tests and 473 seconds was accumulated on three different nozzles. No net throat erosion was measured on any of the liners. The silica liner was charred but none of the charred material was removed during the tests. The chambers were cut into sections after testing was complete and the char layer depth measured.
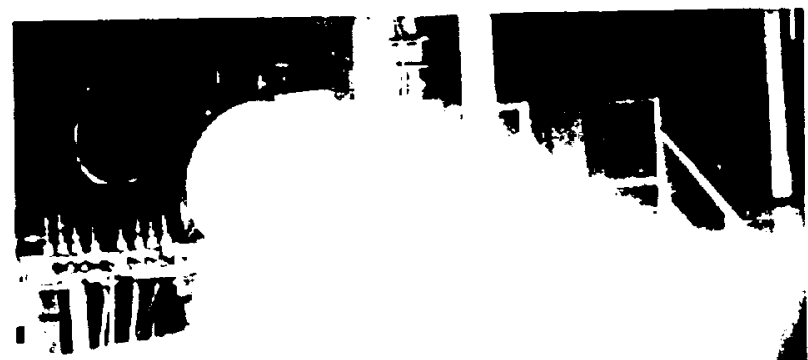

Figure 23-40K Hotfire At MSFC/TS 116

Heat damage in the acoustic cavity and some minor streaking occurred in the $40 \mathrm{~K}$. Since the damage was mostly occurring near the acoustic cavity, we modified the geometry to change the flow path into the cavity. We matched the cavity design used in the $15 \mathrm{~K}$ hardware, but this had no affect. The streaking was later solved with faceplate element geometry changes made on the $15 \mathrm{~K}$. No local overheating or streaking has occurred since these faceplate modifications were made. The test series ended with a successful 150 second test on $40 \mathrm{~K} \# 2$ (second $40 \mathrm{~K}$ nozzle manufactured).

\section{Transition to 60K}

The last few tests of the $40 \mathrm{~K}$ nozzles actually had a Pc above 600 psia (rather than 400 psia) as a pathfinder for the $60 \mathrm{~K}$ hardware. No nozzle performance change was noted at the elevated operating pressures.

\section{C. $(60 \mathrm{~K})$ Flight Design}

The last portion of the program was the design, manufacture and test of the $60 \mathrm{~K}$ Might nozzle design. The $40 \mathrm{~K}$ design was modified by increasing chamber pressure from 400 psia to 633 psia, which gives approximately $60.000 \mathrm{lbs}$. of thrust. The $60 \mathrm{~K}$ nozzles 
were made on the same tooling as the $40 \mathrm{~K}$ nozzles. therefore $60 \mathrm{~K}$ nozzles share the same inner contour as the $40 \mathrm{~K}$ nozzles.

\section{Injector Attachment Design}

The injector flange geometry changed slightly to accommodate the change from the $40 \mathrm{~K}$ injector to the $60 \mathrm{~K}$ injector. The chamfer on the silica leading into the acoustic cavity was changed to match the new acoustic cavity geometry desired for the new design.

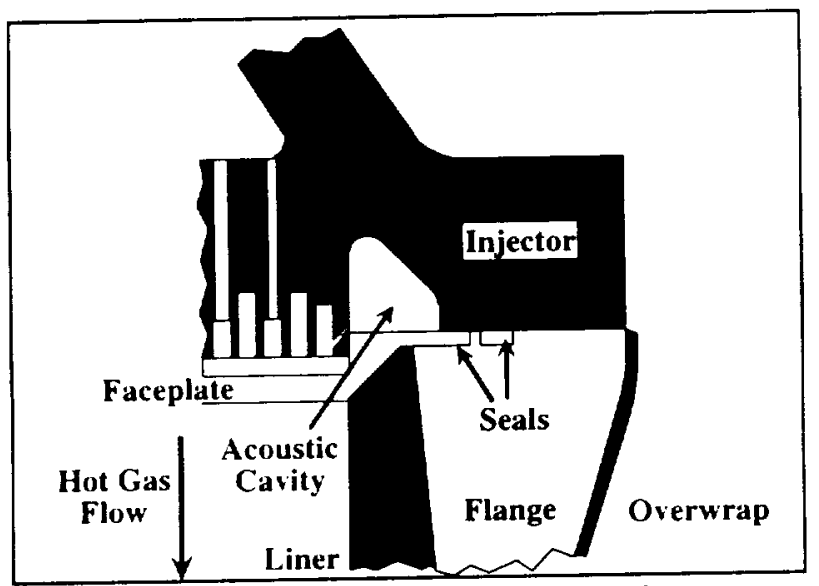

Figure 24 - 60K Injector / Nozzle Altachment

\section{Liner Thickness Change}

Liner thickness was kept almost identical to the $40 \mathrm{~K}$. with a small liner thickness increase at the locations where the brackets are bonded to the nozzle outer surface. This additional liner material was added to provide more thermal protection for the bondline under the external bracket attachments during thermal soakback after the engine has shutdown. Shear pins were also added at these locations to provide increased reliability of this attachment. A small change was made to the overwrap winding pattern to accommodate the changed nozzle outer diameter contour

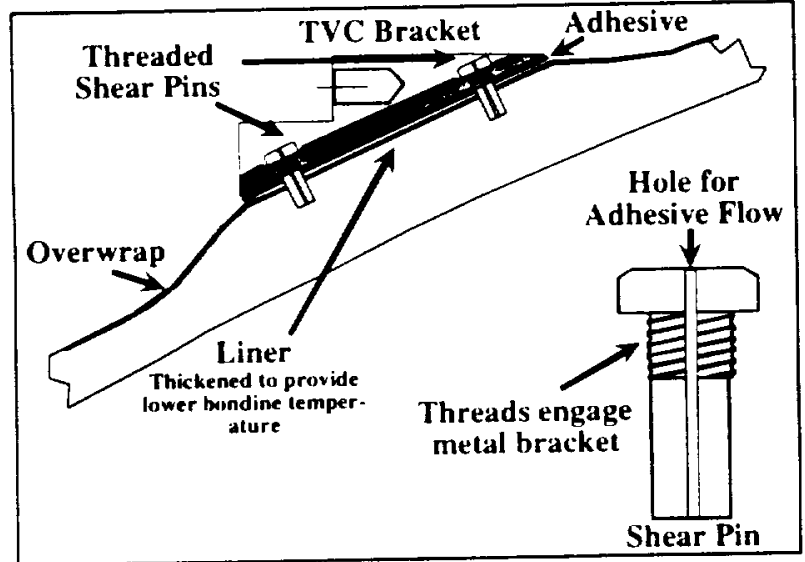

Figure 25 - TVC Altachment Cross Section

\section{Materials and Processing}

After two successful tests of the first $60 \mathrm{~K}$ nozzle, the nozzle broke off just aft of the throat at the start of its third test. An investigation team was formed to explain the failure, and after the cause was found, a "Tiger Team" was formed to correct and improve the materials and manufacturing process of the nozzle.

The cause of the failure was a combination of the following:

- Low strain to failure of the "different but equal" silica phenolic material.

- Degraded bondline between the liner and overwrap.

- Induced stress from CTE mismatch between overwrap and liner,

- Repeated use of a single use nozzle.

One primary reason for this failure can be traced to the change in silica phenolic material in the transition from $40 \mathrm{~K}$ to $60 \mathrm{~K}$ nozzle production. One "flavor" of silica phenolic was used in the $40 \mathrm{~K}$ nozzles, but was discontinued, so a replacement material that met the identical RSRM spec was substituted. We found that this new material had a lower strength and was more brittle. We now use a silica phenolic "flavor" that is as close as the original material as can be manufactured at this time.

Numerous changes and improvements were made to the processing flow of the nozzle based on the findings listed above, and no further anomalies have been found since these processing changes went into effect. We are also developing inspection techniques that allow us to judge the liner delamination depths and debonded areas caused by the post test heat soak through the nozzle wall. Using these techniques, we have been able to retest a nozzle up to 9 times

\section{Analysis}

Detailed CFD, Thermal, Thermostructural and Dynamic analysis using projected flight environments began during the $60 \mathrm{~K}$ program.

\section{Bonded Brackets}

It became necessary to bond a few small brackets to the nozzle for support of other hardware. Two pads (made of molded composite) are bonded onto the nozzle for support of the engine drainlines, and three more were added to support stringer brackets extending from the injector to the bellyband

\section{Thermal Protection System (TPS)}

The overwrap is limited to approximately $300^{\circ} \mathrm{F}$ temperatures due to the epoxy resin. In order to protect the overwrap from the plume radiation and convective environments at high altitude. TPS was applied to the 
surface of the nozzle aft of the TVC ring. No TPS is applied above the TVC ring because that portion of the nozzle is contained behind the Heat Shield on the X-34 vehicle.

\section{FUTURE WORK}

We are currently completing the Fastrac Engine Development testing, with verification testing and X-34 flight certification testing to follow. Because of the extensive database accumulated to date, no significant design changes to the nozzle are anticipated.

There is a sign in an unnamed production facility that reads "There comes a time in the life of every program when you must shoot the engineer and start production". The time came when we had to freeze the nozzle design in order to meet the nozzle production schedule. We have identified several areas of improvement if another application for this nozzle is requested. Significant weight could be saved in the injector flange and the liner material. A CMC (Ceramic Matrix Composite) nozzle extension would save a tremendous amount of weight, and would be easily attached to the ablative design.

Another area of interest that has been mentioned is a nozzle in the $250,000 \mathrm{lb}$. thrust category. The technology and design techniques developed on this nozzle will scale up to a nozzle of this size, and any booster application should result in a nozzle with an increased thrust/weight ratio over the current design.

\section{CONCLUSION}

We are nearing the end of the of this nozzle development, and have enjoyed great success. Although many of our current design requirements are driven by $X-34$, the philosophy, technology and hardware developed in this nozzle could be applied to other sizes and many applications.

\section{ACKNOWLEDGEMENTS}

I thank the entire Fastrac nozzle team for the dedication, good attitudes and the fine technical work that has been accomplished over the entire program. The designers, materials experts, analysts, machinists and the test crew are proud to have worked together and produced such a fine product. I also thank ThiokolSEHO (Science and Engineering Huntsville Operation) for their excellent advice and manufacturing expertise (and the IR\&D funds in the very early development stages). We finish by thanking the management at MSFC for the opportunity to design, fabricate and test a component from beginning to end. There is no better training than to put the theory and analysis into practice.

\section{REFERENCES}

1. J. C. Moise and R. J. Dovach, (AIAA pa;er No. 69442) - "Perfromance of Various Ablative materials In A Large Hydrogen/Oxyegn Thrust Chamber", June 9$13,1969$. 